\title{
Eröffnung der Schule zur sittlichen Erziehung der Jugend.
}

In dicht gedrängtem Saale eröffnete Prof. Füster Sonntag, den 19. September, oben genannte Schule. Seine ergreifende Rede machte manche Thräne inniger Rührung über die Wangen liebender Frauen fließen und seine herzlichen Ermahnungen drangen tief in die Gemüther aller Zuhörer.

Die Theilnahme, welche das deutsche Publikum dem edelen Unternehmen der Gründung einer unter Füster's Leitung stehenden Schule schenkt, sprach sich aufs Unzweideutigste aus. Diese geht gewiß einer großartigen Zukunft entgegen, falls Füster die Seele der Schule bleibt. Denn er ist kein gewerbsmäßiger, in seinem Schuldienste stumpf oder schlaff gewordener Lehrer, sondern ein hoch begabter, mit der Erfahrung reiferer Jahre die Frische und die Wärme der Jugend verbindender Gelehrter.

Die Rede, welche nach Füster Hr. Reffelt hielt, hat uns, aufrichtig gesagt, nicht angesprochen. Wenn unsere Jugend nicht weiter, als bis zu den Gemeinplätzen „,was du nicht willst, daß man dir thu“ und „üb' immer Treu und Redlichkeit“ gebracht werden soll, dann kann sie sich mit den bestehenden Alltagsschulen und Sonntagsschulen begnügen. Auf der Höhe dieser beiden alten Krücken kann der Mensch vielleicht über das Zuchthaus hinwegkommen, allein nimmermehr sich in die Lichtregionen der Freiheit, der Vernunft und der Poesie hinanschwingen.

Mir scheint, der eigentliche Zweck der Sonntagsschule müßte dahin gehen, die Kinder über den Standpunkt spießbürgerlicher Redlichkeit und gemüthseliger Alltagsduselei emporzuheben. Es genügt uns nicht, die heranwachsende Jugend vom Pfade der Mörder und Gauner fern gehalten zu sehen. Wir wollen, daß sie zu aufopferungsfähigen, strebenden und hochherzigen Menschen, zu freiheitsmuthigen Bürgern und zartfühlenden Frauen herangebildet werde.

Wir glauben, das rege Interesse, das wir der Sonntagsschule zur sittlichen Erziehung widmen, am besten dadurch kund zu thun, daß wir gleich in deren Anfange allen wässerigen und abgedroschenen Beimischungen aufs's Bestimmteste entgegen treten.

Der Liederkranz, welcher durch den schönen Gesang: „Brüder, reicht die Hand zum Bunde" und einen zweiten Vortrag viel zur Verherrlichung der Feier beitrug, verdiente sich den herzlichen Dank aller Anwesenden.

Möge der Geist Füster's und des Liederkranzes die neue Schule beseelen! Möge sich dieselbe aber fern halten von den stereotypen Redensarten einer veralteten Moral, welche den Anforderungen unserer Zeit nicht entspricht! 